\title{
OBSERVATIONS ON THE ABSORPTION, DISTRIBUTION AND EXCRETION OF SULPHAPYRIDINE, DAGENAN OR M. \& B. $693^{1}$
}

\author{
By W. HURST BROWN, WILLIAM B. THORNTON, AND J. STUART WILSON \\ (From the Department of Medicine, University of Toronto, and the service of Dr. H. K. \\ Detweiler, Physician-in-chief, Toronto Western Hospital, Toronto)
}

(Received for publication June 19, 1939)

Editorial comment has recently appeared in several of the leading medical journals urging the need of gathering data on the absorption, distribution and excretion of M. \& B. 693 (Dagenan or sulphapyridine) in the human subject. It is evident that an accurate assessment of the potency and toxicity of this drug must await such information. The present communication is based on a study of 90 cases of pneumonia treated by sulphapyridine in the Medical Division of the Toronto Western Hospital between October, 1938 and May, 1939.

From the beginning every case of pneumonia treated by chemotherapy was followed as closely as possible with respect to the dosage, fluid intake and urinary excretion, and daily estimations in the blood and urine of the total, the free and conjugated fractions of the drug. Whenever opportunity presented, specimens of blood, cerebrospinal fluid and pleural effusions were collected simultaneously for assay. Special precautions were also taken to obtain complete collections of urine over the days of actual treatment and for at least four days following cessation of dosage. The method used in all chemical estimations was the method of Marshall et al. (2).

\section{Scheme of dosage}

After the first 20 cases had been treated according to the plan advocated by Evans and Gainsford (1), it was decided to alter the schedule of dosage to permit of an earlier attainment of initially high concentrations of sulphapyridine in the blood. After this time the patients usually received 2 grams every four hours for 6 doses with decrements of $1 / 2$ gram every four hours or every six hours during each of the ensuing twenty-four hours (as illustrated in Figures 1, $2,5)$ until treatment was discontinued. To the

1 This investigation was carried out with the aid of a grant from the Banting Research Foundation. same end the fluid intake was deliberately reduced to below 2,500 cc. per day. In some instances an overemphasis on this point resulted in the fluid intake temporarily falling to levels too far below this figure, with results which receive comment later in this paper.

In Canada the distribution of 2-(p-aminobenzenesulphonamido)-pyridine, or M. \& B. 693 is effected by the firm of Poulenc Freres of Montreal,2 under the name of Dagenan. All of the drug used for oral dosage in the Toronto Western Hospital came from this source and was manufactured in France by the firm of RhônePoulenc. It has been accepted that, chemically, Dagenan is identical with M. \& B. 693, as distributed in England, and sulphapyridine as distributed in the United States. For this reason the term sulphapyridine has been used in this report to denote the drug, except in the soluble form. For the sake of brevity in some of the figures, the designation 693 alone is used, and refers to the 2-(p-aminobenzenesulphonamido)-pyridine, stripped of all sodium and water of crystallization; although reference is made to the conjugated or acetylated form as conjugated 693 .

In March 1939 a supply of the sodium salt of sulphapyridine manufactured by the Calco Company was received through the courtesy of Dr. Perrin H. Long ${ }^{3}$ of Johns Hopkins Hospital. Later, free samples of Soludagenan were received from the Canadian distributors. This preparation is a 33 per cent solution of the sodium salt of Dagenan, contained in ampoules of $3 \mathrm{cc}$. content. Clinical trials of the drug in this form are still in progress.

\section{OBSERVATIONS}

\section{Observations on oral dosage}

All but 2 of the 90 cases treated at some time received sulphapyridine by mouth; some of these received supplemental intravenous, or intra-

2 The authors wish to record their appreciation to Poulenc Freres for providing free supplies of Dagenan and Solu-dagenan for use in this study.

3 The authors are pleased to acknowledge their indebtedness to Dr. Perrin H. Long and to Dr. E. K. Marshall of Johns Hopkins University for their help and cooperation. Dr. Marshall tested Dagenan as used by us against sulphapyridine, as used in Johns Hopkins Hospital, for toxicity in the mouse and found no significant difference. 
muscular sodium sulphapyridine or Solu-dagenan. General observations on the results of oral dosage will first be presented and the tentative conclusions reached will be subjected to criticism in a later part of the report dealing with cases treated by injection.

\section{Observations on absorption}

It was early and frequently observed that, independent of the factors of weight, fluid intake, vomiting, sweating, bowel activity, urinary excretion and gastric acidity, there was a wide discrepancy in the levels obtained in the blood on a standard scheme of dosage. In the entire series the concentration of non-conjugated sulphapyridine hereafter called free in the blood varied from 2.2 to $12.8 \mathrm{mgm}$. per $100 \mathrm{cc}$. at the end of twenty-four hours of therapy. After due allowance was made for all the factors named, there still remained gross differences. These variations must, therefore, be chiefly attributed to differences in the rate and degree of absorption of sulphapyridine from the gastro-intestinal tract. Some have stated that the rate of absorption is increased if the tablets are administered as a powder. Confirmation of this is not possible in the present series. The stomach of one patient who died ten minutes after receiving four 0.5 gram tablets of Dagenan by mouth was examined thirty minutes postmortem and found to contain amorphous material giving a positive test for sulphapyridine. No sign of the tablets, as such, could be found either in the esophagus, stomach or duodenum.

\section{Observations on distribution}

(a) The drug is apparently absorbed in the free or nonacetylated form. Conjugation usually takes place gradually with a resulting depletion of the free form. For this reason the highest relative values for the free form in the blood are commonly found in the first day of treatment.

(b) Although in most cases a parallelism exists between the levels in the blood of the free and conjugated forms from day to day (Figures 1,2 ), in about one-fifth of the cases this is not true. In these instances, there appeared to be an unusually rapid conjugation of the drug and it was not infrequently found that an estimation of the free form alone gave no reliable indication of the total concentration of the drug in the blood
(Figure 3). This was particularly noticed in cases which developed renal insufficiency. In these the concentration of the total sulphapyridine in the blood often rose concurrently and abruptly to very high levels (Figures 5,6 ). Since the power to conjugate the drug was apparently not impaired, concentration levels of the total and free forms rapidly diverged. In some of the cases, indeed, it seemed that the attainment of high blood levels accelerated the rate of conjugation (Figures 5, 6).

In view of Marshall's statement (3) that acetylated sulphapyridine is more toxic than the free form, these findings have a manifest importance. Some of the serious toxic effects were observed to occur in those cases which, at some time or other, showed inordinately high values in the blood of the conjugated fraction.

(c) In only one of 16 cases in which the concentration of the cerebrospinal fluid was estimated at the same time as the blood, was the level in the cerebrospinal fluid as high as that in the blood. In the majority it was about 65 per cent of the blood concentration (Figures 1, 2). In all instances, a disproportionately high percentage of the free form of the drug was present in the cerebrospinal fluid as compared with blood values simultaneously obtained. In 8 of 16 cases there was practically no conjugated drug in the spinal fluid.

(d) A large number of the estimations on the pleural fluid were rendered suspect by the use of novocaine as an anaesthetic. In those samples obtained without using an anaesthetic the values were never less than the concentration in the blood.

(e) The drug was recovered from the vomitus, sputum, and feces of patients under therapy. In cases on oral dosage the amounts recoverable in the feces were very large indeed.

(f) Chemical assays of the organs of 4 cases showed that sulphapyridine is unequally distributed among them in terms of concentration per 100 grams of tissue. It is high in the kidney (where contamination by urine is an important factor) and next highest in the liver. It is variable in the spleen and low in the brain, bile, and body fat. In these tissues the percentage of drug in the conjugated form was found to be lower than in the heart's blood. 


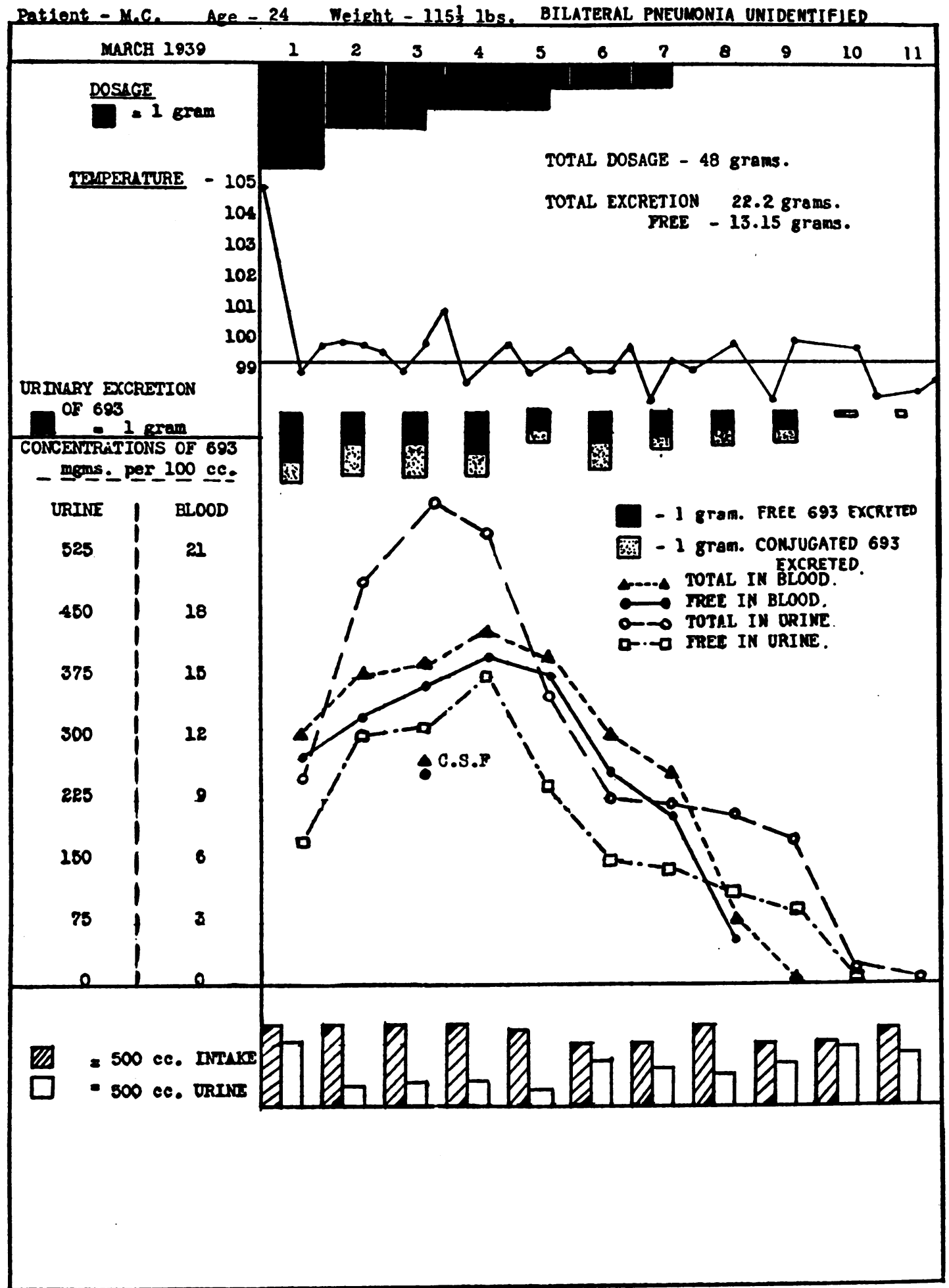

Fig. 1. A Typical Case of Heavy Dosage of Dagenan

Note the parallelism between the concentrations of the free and total drug in the blood, the levels in the cerebrospinal fluid, the time required for complete excretion of the drug. The excretion of the free form in this case was unusually rapid especially in the first 24 hours. 


\section{Observations on excretion}

(a) There can be no doubt that the urine constitutes the main channel of excretion of sulphapyridine from the body. This is particularly well illustrated in cases in which renal function is defective (Figures 5, 6, 7). Provided that urinary excretion was not impaired, the administration of large quantities of fluid by mouth, or especially by vein, decreased the blood concentrations rapidly (Figures 2, 5, 6).

The kidney has the power of concentrating the drug to a very remarkable extent. Five cases were seen in which the concentration of total sulphapyridine in the urine rose to over 500 and in 3 cases to over $600 \mathrm{mgm}$. per $100 \mathrm{cc}$. of urine. In only one of these, however, did the ratio of

Patient - F.L. Age -36 Weight - $157 \frac{1}{2}$ Ihs. PNEUMOCOCCUS TYPE IV. RIGHT LOWER LOBE.

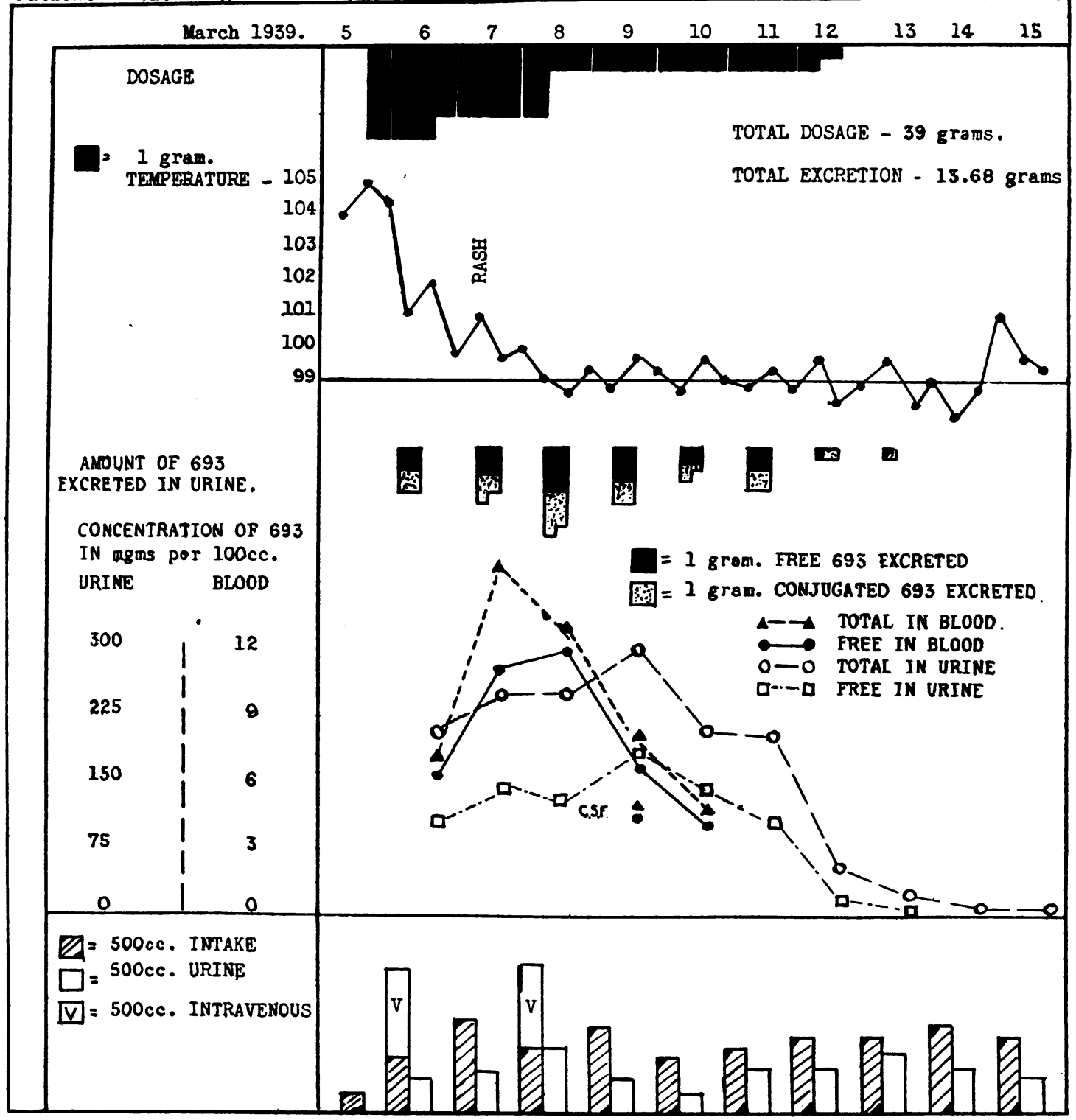

Fig. 2. The Effect of Fluid Intake on the Blood Levels and on Urinary Excretion of the DRUG

Total excretion is complete in 72 hours. Note C.S.F. Levels. Note rate of excretion of free and conjugated forms in the urine compared with the blood levels. 


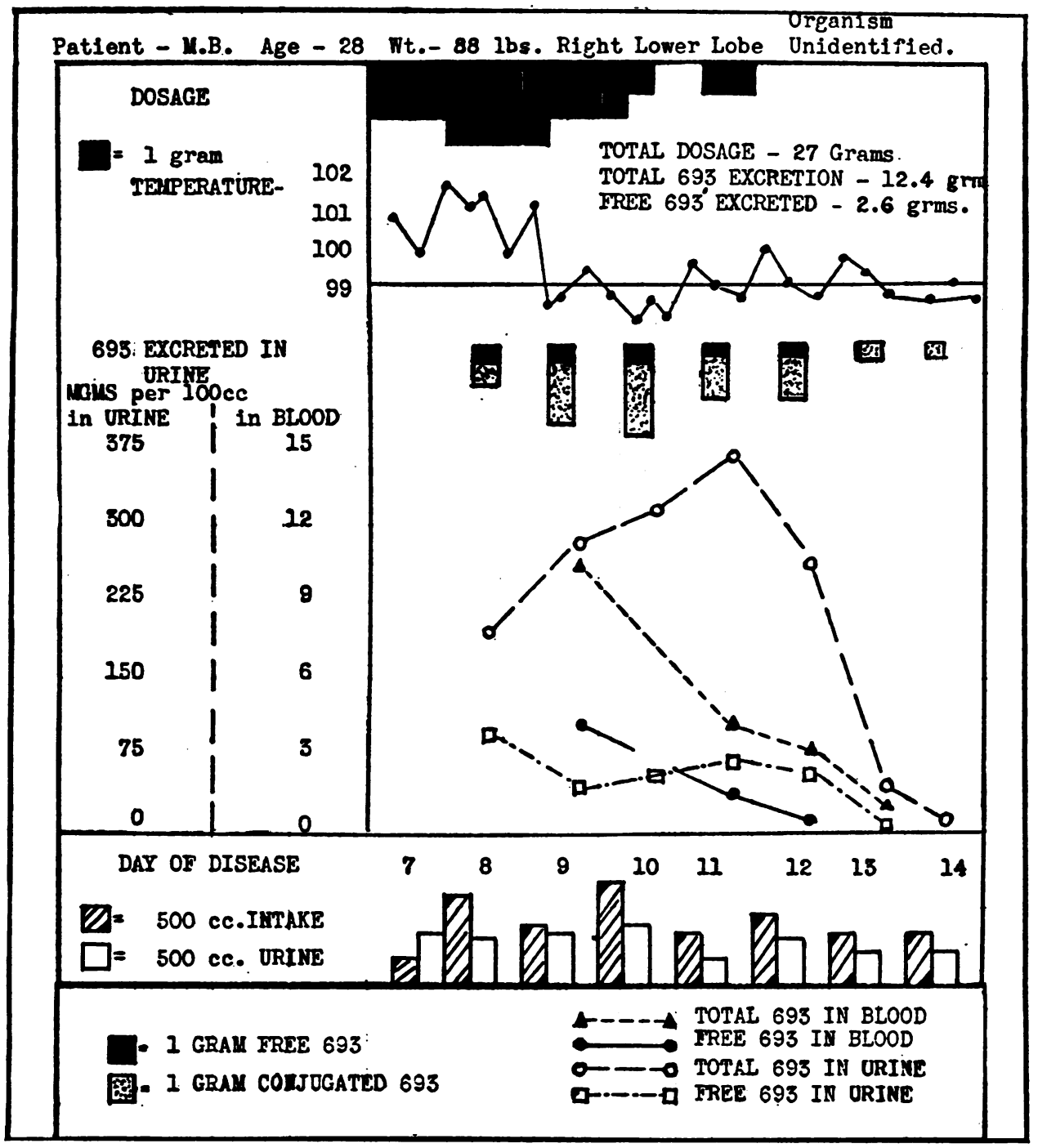

Fig. 3. An Example of Rapid Conjugation with Rapid Excretion of the Acetylated ForM IN THE URINE

concentration of total drug in the urine to the concentration of total drug in the blood reach 40 . In the great majority it was nearer 20 to 25 . This is in contrast to experience with sulphanilamide where the ratio may often reach 40 . This finding may have a bearing on the relatively slow excretion of sulphapyridine from the body. In the surviving cases which were treated by oral administration alone, the last measurable quantity of sulphapyridine disappeared from the blood in sixty hours and from the urine, excepting very faint traces, in ninety-six hours after the final dose had been given (Figures 1, 2, 4, 5, 6). (b) In view of the above findings, it was anticipated that a very considerable proportion of the total amount of drug ingested would be recovered in the urine (6). Even when the blood concentrations were high, indicating a high degree of absorption, the amounts recovered in the urine were remarkably low (Figures 1, 2, 3, 4, 6). In only 3 cases, in which absorption was apparently very rapid, was as much as 50 per cent of the total sulphapyridine given by mouth recoverable in the urine, and in most instances less than 33 per cent was recoverable.

(c) It was generally found after the first 


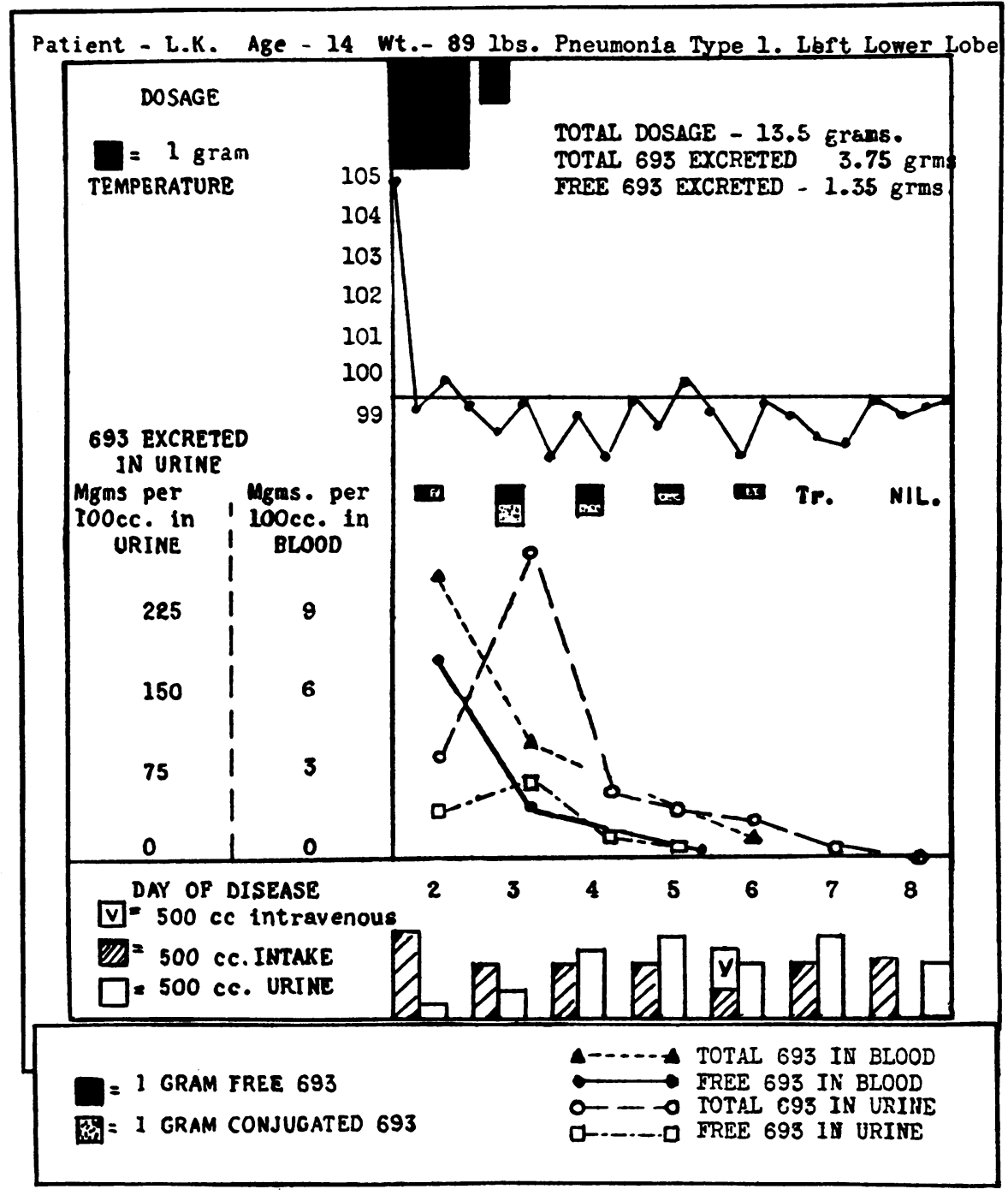

Fig. 4. Poor Absorption of Oral Doses and Complete Excretion in 96 Hours

twenty-four hours that the free form was not as rapidly excreted as the conjugated form (Figures $1,2,3,4,6)$. The occurrence of oliguria (less than $300 \mathrm{cc}$. of urine excreted in twenty-four hours) in 6 cases and of anuria in 3 cases during treatment was associated with abnormally high blood N.P.N. values, an increase in the total concentration of sulphapyridine in the blood, and a marked and very rapid rise in the blood concentration of the conjugated fraction (Figures 5,6). Moreover, although there were exceptions, it was the rule that the concentration of the free form in the urine was disproportionately low as compared to the concentration of the total sulpha- pyridine in the urine, having regard for the existing levels of both in the blood at the time.

\section{Intravenous and intramuscular injections}

There are obvious disadvantages attending an attempt to draw conclusions pertaining to the title of this report from clinical cases receiving prolonged dosage by mouth of a highly insoluble drug. Comparisons of the concentrations attained in blood and urine with the dosage are open to too many undeterminable influences. For this reason, it is of interest to record in more detail the observations in 4 of the cases in which injections of the soluble form of the drug were 


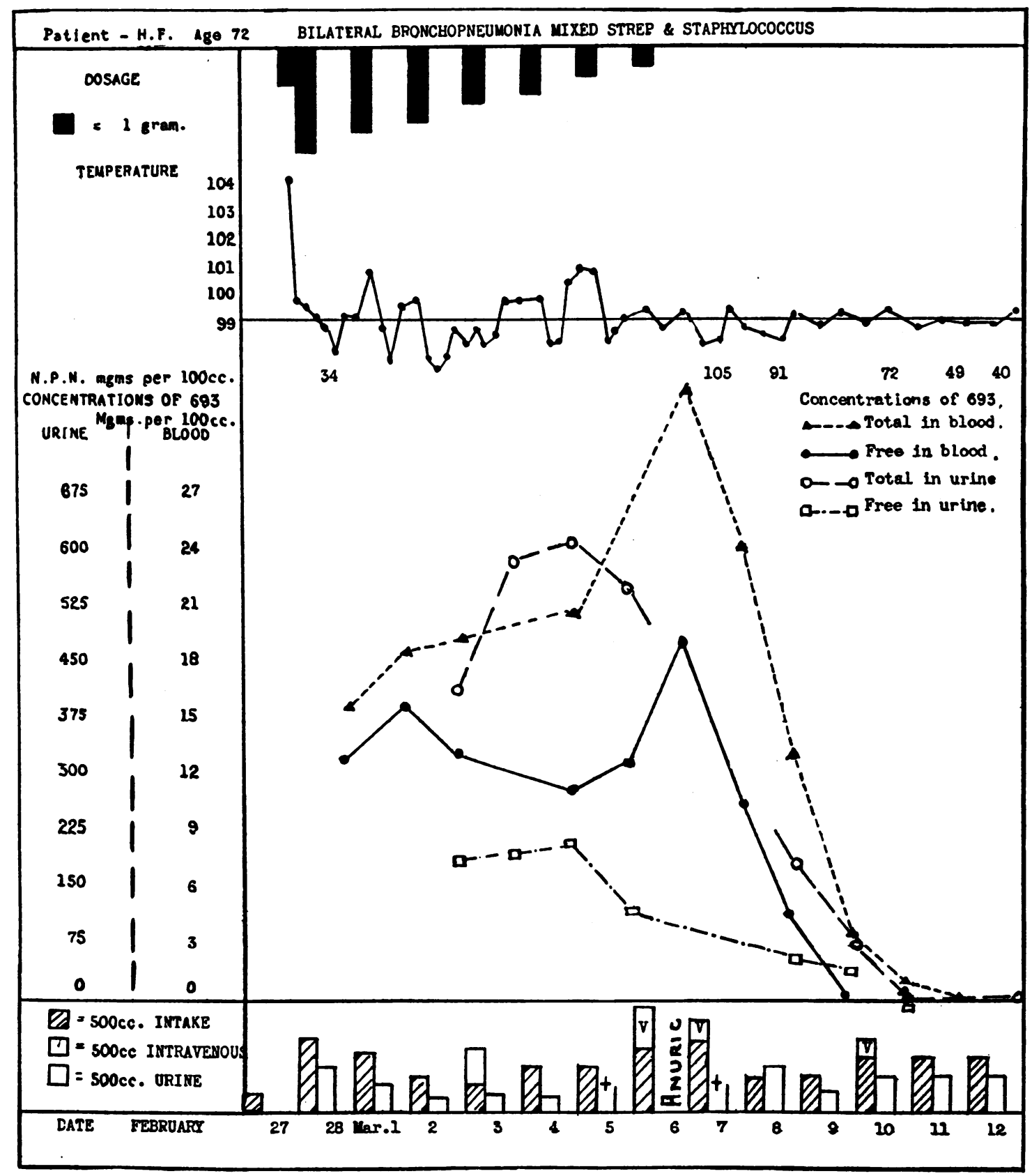

Fig. 5. The Effect of Oliguria and Anuria (Acute Renal Insufficiency) on the N.P.N. and the Concentrations of the Drug in the Blood

There seems to be an acceleration of the rate of acetylation. Note the rapidity of excretion following restoration of renal function. 


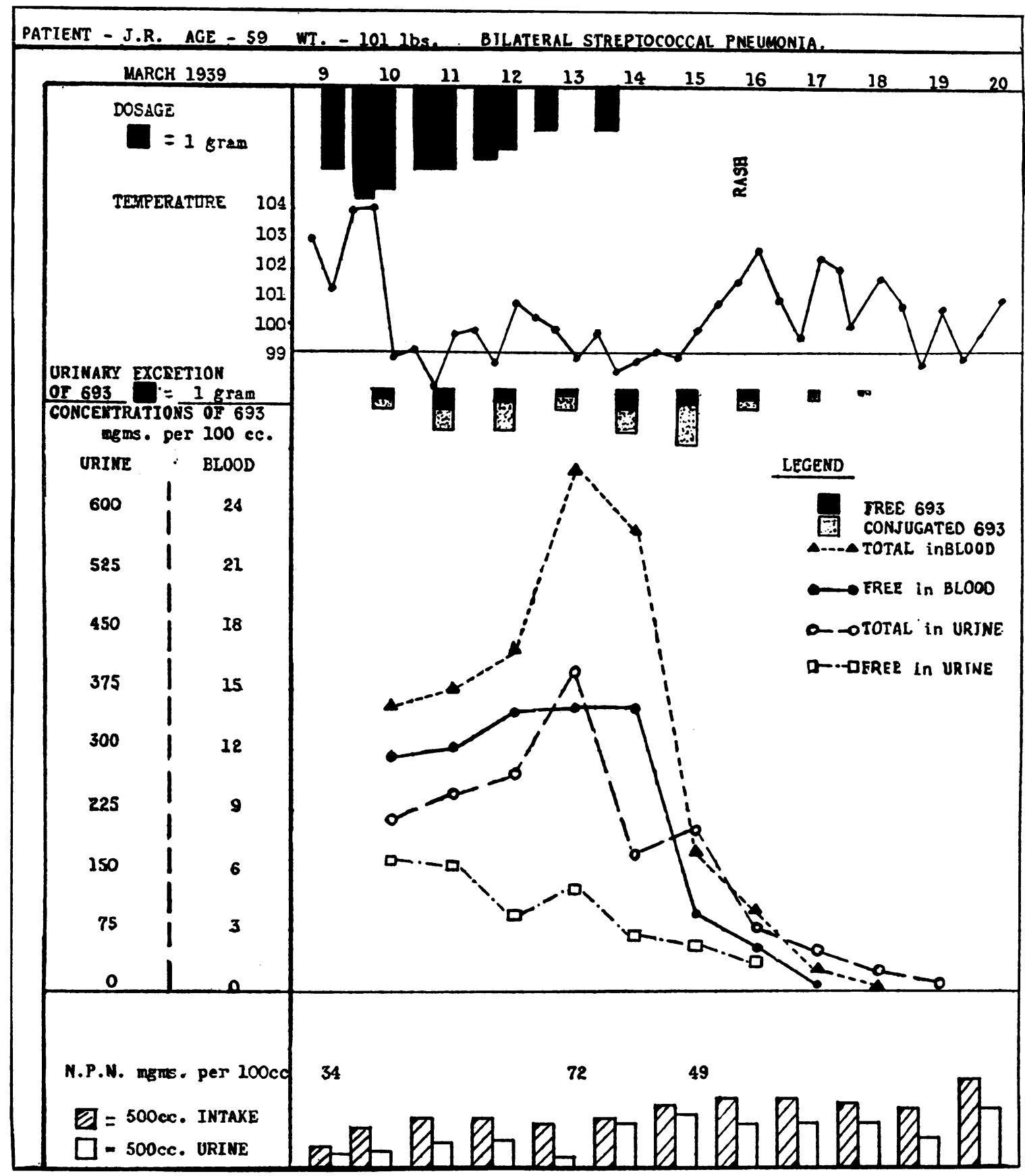

Fig. 6. The Effect of Acute Renal Insufficiency (Compare Figure 5); Possibly Due to an Inadequate Fluid Intake on the N.P.N. and Concentrations of the Drug in the Blood

An abrupt rise in the rate of acetylation (see blood levels) coincides with oliguria. Extremely rapid excretion follows the discontinuance of chemotherapy and restoration of renal function without a great increase in the fluid intake. Note excretion of the conjugated fraction. 


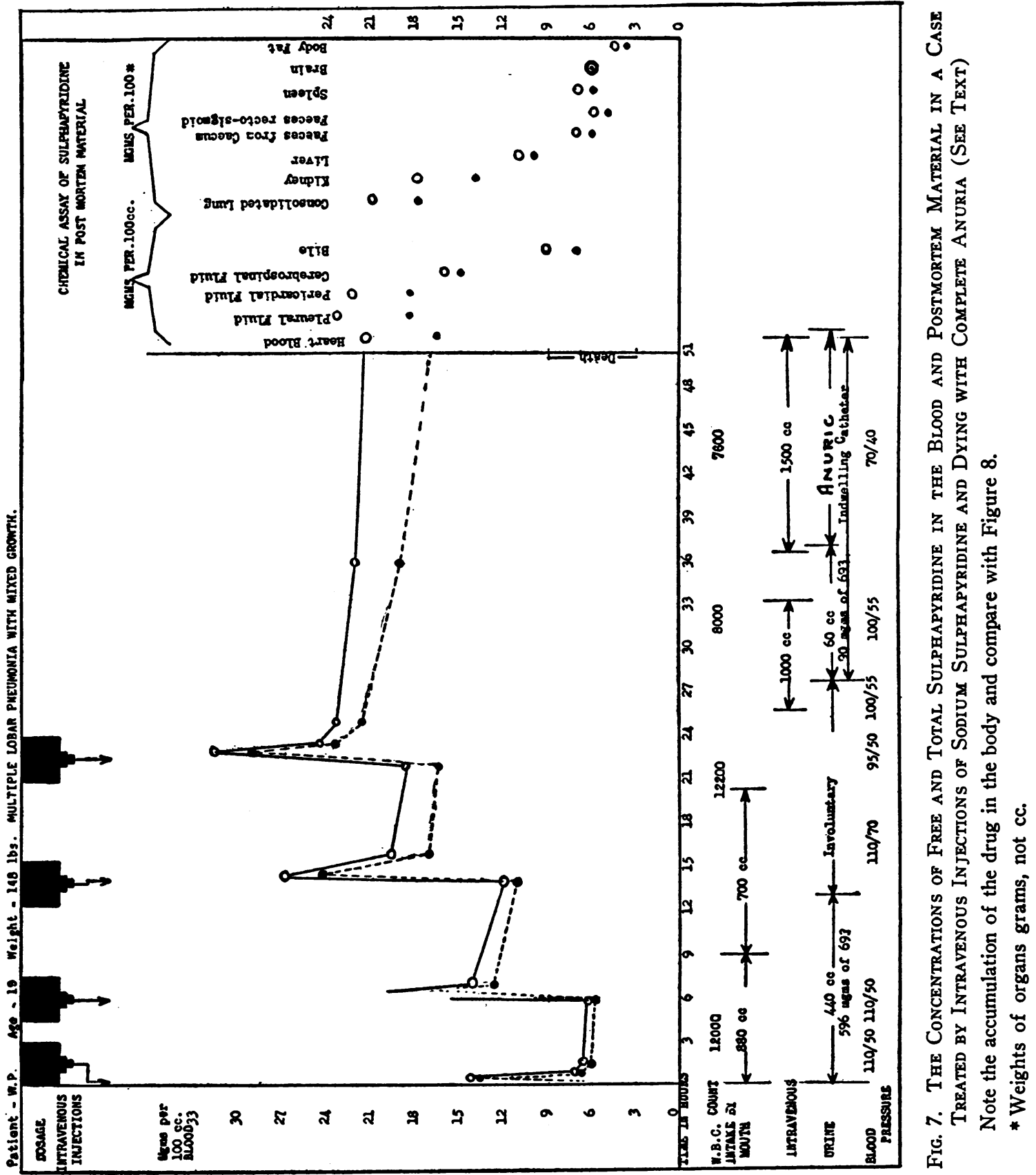


used. From a study of these it was expected that more definite pronouncements regarding the tentative conclusions already noted might be justified.

\section{PROTOCOLS}

\section{Case 1}

In the first case, a boy of 16 weighing 134 pounds, 2 intravenous injections of 3 grams each of 5 per cent sodium sulphapyridine were made at nine-hour intervals. The blood concentrations, attained half an hour after the first injection was completed (fifteen to eighteen minutes were taken to inject the fluid), were $6.9 \mathrm{mgm}$. per 100 cc. total drug, and $6.4 \mathrm{mgm}$. per $100 \mathrm{cc}$. free. Nine hours later, and immediately before the next injection, the values were 5.4 total and 4.8 free. Eight and sixteen hours after this second injection the levels were respectively 7.0 total and 6.6 free, and 5.8 total and 4.5 free. In the first twenty-four hours the fluid intake was 3,000 cc. and the urinary output, which contained 1.47 grams of sulphapyridine, was 1,100 cc. Sulphapyridine continued to be excreted in measurable concentrations in the urine until the fourth day, and in traces until the sixth day. Measurable concentrations of the drug in the blood were present until the second day after the last injection, and in traces for the next two days. Although 6 grams in all of the sodium salt were injected, the actual amount of sulphapyridine was 5.16 grams. Of this quantity 3 grams or 60 per cent were excreted as conjugated and free sulphapyridine in the urine, only 1.85 grams or 36 per cent being in the free form.

This patient made a rapid and uninterrupted recovery from pneumococcal pneumonia Type II without further chemotherapy. The Francis test became positive fortyeight hours after admission (the 5th day of his disease).

\section{Case 2}

The second case requires a more detailed exposition. A young man (Figure 7), 19 years old, weighing 148 pounds, was admitted in a moribund condition on the night of April 16, 1939. He was very pale, restless and continually grimacing. Pulse-110, respiration-30, temperature-105, and blood pressure 120/60. The physical signs were those of frank consolidation of the left lower lobe, but his condition was disproportionately grave considering the apparent extent of lung involvement. Oral therapy by sulphapyridine was impossible and it was thought wise to administer intensive treatment with sodium sulphapyridine intravenously at once. This was given as a 5 per cent solution in doses of $3.8 \mathrm{grams}$ in $70 \mathrm{cc}$. of distilled water. Fifteen to eighteen minutes were taken for each injection. Five minutes after each injection was completed, a sample of blood was taken from the opposite arm, except on one occasion (after the second injection), when twenty minutes elapsed before the sample was taken. After the third injection the results of cultures were reported. The blood cultures were consistently negative. Pneumococcus Type XXIII and staphylococcus aureus were present in the sputum. On mouse passing both were again recovered but the heart's blood of the mouse yielded only staphylococcus aureus in pure growth. This was considered to be a significant indication of the invasive properties of the staphylococcus. The pneumonic process seemed to be extending although the temperature had fallen from 105 to 103 and the patient seemed slightly better. It was now considered likely that the staphylococcus was the responsible organism and in view of reports (4) in the literature attesting cures of staphylococcal aureus septicaemiae by M. \& B. 693, it was decided to give another injection after an eight-hour interval in the hope that by maintaining high blood levels a cure might be obtained.

No untoward reaction to intravenous injections had previously been experienced but, during the fourth injection phase, the great restlessness of the patient abruptly gave way to an ominous quietude, almost as if an anesthetic were being administered. There was a period of collapse and the blood pressure fell from $115 / 70$ to $95 / 50$. These events were clearly the results of the injection and largely disappeared in forty-five minutes when the blood levels were at a demonstrably lower level. A comparison of Figures 7 and 8 illustrates how much the blood levels anticipated in view of previous cases were exceeded by the third and fourth injections. This unexpected and undesired accumulation of the drug must again be attributed to renal failure-in part, no doubt, abetted by the low filtration pressure. Complete anuria was present during the last ten hours of life and, in the light of past experience, it is reasonable to attribute part of the renal failure to the direct action of the drug. It is noteworthy and, under the circumstances, to be expected that the administration of almost $2500 \mathrm{cc}$. intravenously of 5 per cent glucose in saline during the twenty hours following the fourth injection had, in this instance, no effect in combatting the enormous accumulation of the drug. It is proof positive of the importance of free renal excretion in relation to intravenous or oral therapy with chemicals of this type.4

Another finding of importance is illustrated by Figures 7 and 8-namely, that immediately after any intravenous injection, extraordinarily high concentrations of the drug are present in the blood. After a few minutes these fall rapidly and in thirty to sixty minutes distribution has been completed. It is not easy to understand, however, how the body is able to conjugate the free form as rapidly as is demonstrated in these cases. In the case under consideration, excretion of the free form is not as rapid as the excretion of the conjugated form. This is shown by the relatively more rapid fall of the total levels and by the relative amounts of the two forms in the urine first secreted. After the fourth injection, urinary excretion was practically at a standstill and there was no appreciable fall in the total concentrations in the blood. The concentrations of the free form did, however, gradually fall owing to the continuance of acetylation.

4 The $\mathrm{pH}$ of solutions of sodium sulphapyridine or Solu-dagenan as used in these cases was about 11 . 


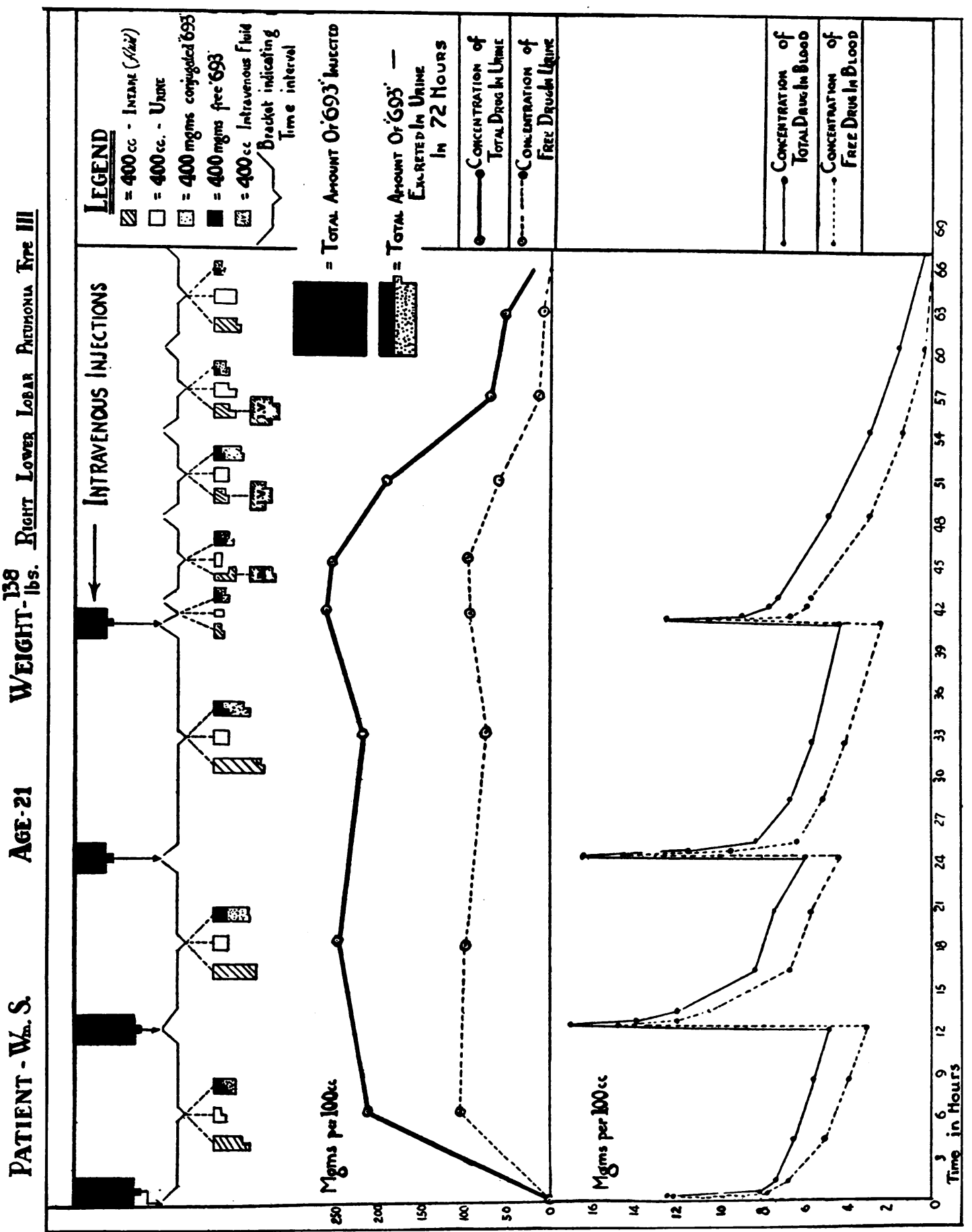

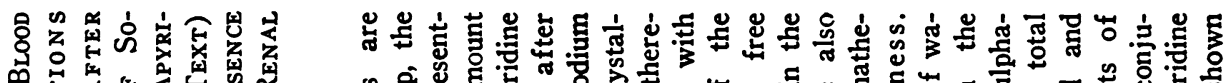

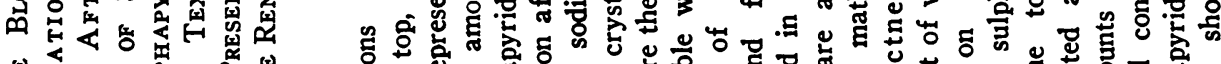

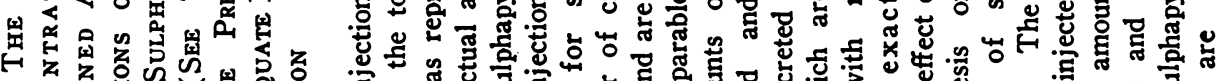

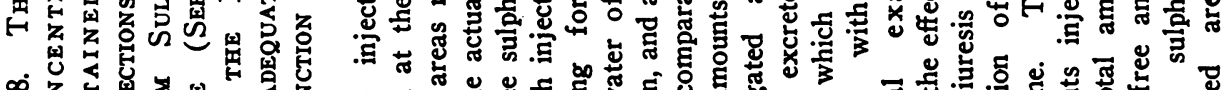

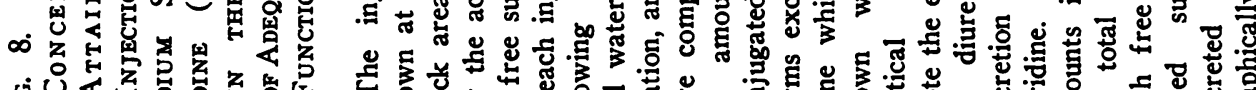

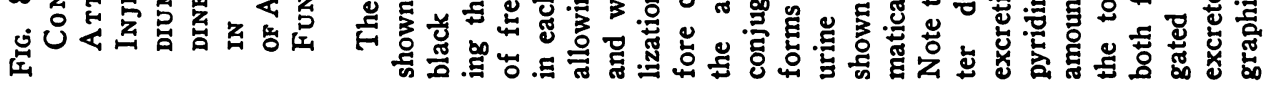


An autopsy held one hour after death established the following anatomical diagnosis: bilateral lobar pneumonia; multiple lung abscesses; bilateral pleurisy with effusion; pleural adhesions; cerebral edema; fatty liver; septic spleen; toxic renal damage.

The abscesses were found in all five lobes of the lungs. From these staphylococcus aureus was cultured in pure growth. No pneumococci were present in any cultures from the lungs. The cultures of the blood from the heart yielded staphylococcus aureus only.

The kidneys were described as being slightly swollen with widening of the cortex and bulging of the cut surface. No hemorrhages were present. Microscopic studies showed a moderate degree of disintegration of the cells of the first convoluted tubules and deposits of pigmented chemical crystals lying in the tubules. No casts were seen and only a small amount of debris was contained in the lumina of the tubules. There was no evidence of actual obstruction of the tubules. The glomeruli were apparently normal.

The liver had obviously undergone much fatty change and on microscopy this was easily seen in fine globules uniformly distributed throughout the liver cells in all areas. This has invariably been noted in all our cases dying while on sulphapyridine therapy. It is, however, impossible, in our view, to attribute these changes to the employment of sulphapyridine in treatment. The most striking case of liver damage encountered received 10 grams of the drug by mouth in twenty-two hours but the maximum concentration attained in the blood was only 4.9 total and 2.2 free mgm. per $100 \mathrm{cc}$. The liver was so fatty that it floated easily in water but the damage should, in this instance, be attributed to the toxicity resulting from the disease rather than chemotherapy. ${ }^{5}$

The organs and various fluids and tissues were subjected to chemical analysis for their content of sulphapyridine with results as noted in Figure 7 . It will be noted that the heart's blood, pleural fluid, and pericardial fluid yielded high assays for the drug. The lung (consolidated) also had very high concentrations as had the kidney. The other organs and the bile yielded smaller concentrations. As has previously been pointed out, the C.S.F. had a relatively high content of the free form but much less conjugated drug than the blood. The brain in this instance contained none of the conjugated drug. This result has been confirmed in 3 other cases in which the amount of the conjugated form never exceeded 5 per cent of the total. No explanation can at present be offered for this remarkable finding.

The bowels had not been emptied since chemotherapy was begun. It is therefore of interest to compare the concentration of the drug found in the feces from the rectosigmoid junction with that in the feces from the cecum and in the bile. The findings indicate that an appreciable amount of the drug is excreted into the bowel independently of the bile, but that the concentrations are not high in the bowel content.

5 The authors wish to thank Dr. George Shanks for his reports on the autopsy material.
The lowest concentrations were obtained in body fat taken from the abdominal wall and, here again, the free form greatly predominated. The following were the total quantities contained in the various organs.

TABLE I

Sulphapyridine

\begin{tabular}{|c|c|c|c|c|c|}
\hline \multirow{2}{*}{ Organ or material } & \multirow{2}{*}{ Weight } & \multicolumn{2}{|c|}{ Free mgm. } & \multicolumn{2}{|c|}{$\begin{array}{c}\text { Conjugated } \\
\text { mgm. }\end{array}$} \\
\hline & & $\begin{array}{l}\text { In } 100 \\
\text { grams }\end{array}$ & $\begin{array}{l}\text { Whole } \\
\text { organ }\end{array}$ & $\begin{array}{l}\text { In } 100 \\
\text { grams }\end{array}$ & $\begin{array}{l}\text { Whole } \\
\text { organ }\end{array}$ \\
\hline 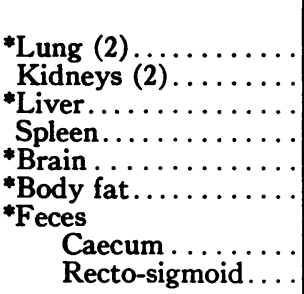 & $\begin{array}{r}\text { grams } \\
1850 \\
335 \\
2050 \\
300 \\
1650\end{array}$ & $\begin{array}{r}18.0 \\
14.0 \\
10.0 \\
6.0 \\
6.0 \\
4.5\end{array}$ & $\begin{array}{r}351 \\
47 \\
201 \\
18 \\
106\end{array}$ & $\begin{array}{l}3.0 \\
4.0 \\
1.0 \\
1.0 \\
\\
0.8\end{array}$ & $\begin{array}{l}58.5 \\
11.0 \\
20.5 \\
21.0\end{array}$ \\
\hline
\end{tabular}

* Chemical assay was carried out on only a portion of the total organ or material in these instances and the possibility of unequal distribution of the drug is not precluded.

It seemed possible, before 4 fatal cases were investigated in this way (with results which throw much doubt on the validity of such calculations), to estimate the total amount of drug in the body from the concentrations in the blood and the body weight. Such calculations depend upon the assumption that the sulphapyridine is distributed in almost equal concentrations to all tissue fluids and it is apparent that this may not be the case. Using Peters' researches (5) as a basis, and by the arbitrary assumption that 70 per cent of the body weight is distributable fluid of a specific gravity (for pooled fluid) of about 1020 , the amount of sulphapyridine in the body one hour after the first injection is by calculation 3.1 to 3.2 grams and two hours after the fourth injection about 11.8 grams.

Each of the four injections contained 3.8 grams of sodium sulphapyridine. Almost exactly 14 per cent of sodium sulphapyridine is made up of sodium and water of crystallization; therefore the amount of sulphapyridine contained in each injection is actually not 3.8 grams but about 3.3 grams. At the end of the first hour, therefore, a little less than 3.3 grams should be present in the body and two hours after the last injection, 13.2 grams minus the amount lost in vomitus, saliva, sweat and urine should be present. The calculated values bear a closer relationship to the actual 
amounts injected than would be expected from the results of chemical assay of the various organs, although these after all constitute only a very small percentage of the total body weight.

\section{Case 3}

A third case, successfully treated by intravenous sodium sulphapyridine, is illustrated in Figure 8 . This young man was aged 21 and weighed 138 pounds. He was admitted on April 26, 1939, with Type III pneumococcal pneumonia as shown by blood and sputum cultures and by mouse inoculation. He received intravenously two injections of 3.8 grams, followed by two injections of 2 grams of sodium sulphapyridine at the intervals noted in Figure 8. He responded well to this therapy but later developed an empyema for which he was treated with Dagenan by mouth for three days until it was established that only staphylococcus aureus was present in the pleural pus, and resort was had to surgical treatment.

In this case no impairment of renal function occurred although $\mathbf{1 1 . 6}$ grams of the sodium sulphapyridine were injected over a period of forty-eight hours. There was no sign of accumulation of the drug. The administration of $5170 \mathrm{cc}$. of fluid (3,000 cc. intravenously) in the twenty-six hours following the last injection reduced the blood level from $7.5 \mathrm{mgm}$. per $100 \mathrm{cc}$. of the total drug per $100 \mathrm{cc}$. blood to a trace. Complete figures are available for urinary excretion of both the free and total moieties for the first seventy-two hours. These are represented with mathematical exactitude in Figure 8. It will be seen that, expressed as pure or free sulphapyridine, the patient received a net total dosage of 10 grams after making allowance (1.62 grams) for sodium and water of crystallization. Of this total amount 5.1 grams had been excreted in the urine at the end of seventy-two hours and of this only 2 grams were in the free form.

It is of particular interest to compare the blood levels attained in this patient on intravenous therapy with those later attained when sulphapyridine was given by mouth. The daily fluid intake was purposely maintained at 2,000 cc. during this period. In Table II the results are noted, each blood sample being taken four hours after the preceding dose.

Twelve hours after dosage was discontinued only a trace was present in the blood.

It is evident that the plan of dosage by mouth maintained a more constant level in the blood. In all, 27 grams were given by mouth over a period of seventy-two

TABLE II

Blood concentrations (free) reached in patient $W . S$. (Figure 8) on oral administration of Dagenan

Blood

Dosage

grams concentration
of free drug $100 \mathrm{cc}$.

1 dose of 2 grams .................

After 2 grams q.4.h. for 4 doses...........

After 2 grams q.4.h. for 6 doses........... 5.7

After $1 \frac{1}{2}$ grams q.4.h. for 6 doses.........

After 1 gram q.4.h. for 6 doses............ 4.2 hours, as against 10 grams in the earlier period of seventy-two hours of intravenous therapy, without achieving significantly higher levels. It must be concluded therefore, that more than half of the sulphapyridine given by mouth was not absorbed.

\section{Case 4}

The following case admitted with pneumococcal pneumonia on May 7, 1939, the first day of his disease, deserves mention since it is one of the 4 cases on injection treatment which were studied closely. The protocol of this man is shown in Table III. It will be noted that he was first treated with intramuscular Solu-dagenan alone and two days later sulphapyridine by mouth. The intramuscular injections consisted of 33 per cent Solu-dagenan put deeply into the gluteal muscles. At first he reacted well to intramuscular therapy but on the second day (May 9), his infection escaped from chemotherapeutic control, although his levels were still high. Despite a falling leukocyte count, clinical signs of extension of the pneumonia ruled out chemical toxicity as the cause of the increased fever. Sulphapyridine therapy by mouth in full doses was therefore begun with an ensuing improvement in his general condition and a fall in temperature. The white count now fell to what experience has shown to be ominously low levels (total granulocyte count2,200 per $\mathrm{cm}$.). The drug was then discontinued and the administration of very large quantities of fluid by mouth and 10 per cent glucose saline intravenously was begun. This resulted in a very rapid removal of the drug from the body. The total leukocyte count began at once to rise but even ten days later the polymorphonuclear cells were only 60 per cent of the total leukocytes. The patient developed a hepatitis as noticed in the protocol and finally proceeded to a complete cure, being discharged from hospital on May 28, 1939.

The following points are of importance:

1. The blood concentrations attained after intramuscular injections are naturally not characterized by the sharp peaks already seen in cases treated intravenously. There is, on the other hand, a gradual but fairly rapid rise in the blood levels which reach their maximum in about three to three and a half hours after which, with normal fluid intake, they begin slowly to fall. The greatest increments after each injection occur when the initial blood levels are low; thus 2 grams at first raised the total concentration in the blood from zero to $4.2 \mathrm{mgm}$. per $100 \mathrm{cc}$. and the free form to $4 \mathrm{mgm}$. per $100 \mathrm{cc}$. in three hours, while the fourth injection of 1 gram raised the concentrations from 8.2 total and 6.7 free to 9.8 total and 7.9 free in three hours.

2. It seems that the higher the concentration of the drug in the blood the more rapid the con- 
jugation. This has already been remarked upon in the cases receiving sulphapyridine by mouth. It is, however, noteworthy that the period during which liver damage became evident (May 12 and 13) coincided with a very low concentration in the blood of the conjugated fraction. As the liver has been stated to be the chief, if not the only, organ concerned in acetylation (7), it is possible that the marked diminution of the conjugated fraction in the blood after May 12 is thus explained. It must be borne in mind, however, that there was also a very rapid excretion of the drug in the urine during this period.
3. The substitution of sulphapyridine by mouth for intramuscular injections on May 9 resulted in a rapid absorption of the drug and the attainment of very high levels in the blood $(18.3 \mathrm{mgm}$. total and $15.5 \mathrm{mgm}$. free per $100 \mathrm{cc}$.). The unusually large amounts absorbed were more completely excreted in the urine than in any other case in the series. The total dosage administered by both methods was something less than 23 grams (allowing for sodium in the molecule of Solu-dagenan) and the amount excreted in the urine was somewhat more than 19 grams. (Traces continued to appear in the urine from

TABLE III

Patient, K. H. Age 32. Weight 124 pounds. Type III pmeumococcal pneumonia, right lower lobe. Blood cultures repeatedly negative.

\begin{tabular}{|c|c|c|c|c|c|c|c|c|c|c|c|c|c|c|c|}
\hline \multirow[b]{2}{*}{ 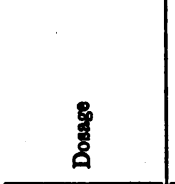 } & \multirow[b]{2}{*}{$\frac{8}{0}$} & \multirow[b]{2}{*}{ 岸 } & \multicolumn{2}{|c|}{$\begin{array}{l}\text { Concentration } \\
\text { of Dagenan } \\
\text { in blood }\end{array}$} & \multicolumn{2}{|c|}{$\begin{array}{l}\text { Concentration } \\
\text { of Dagenan } \\
\text { in urine }\end{array}$} & \multirow{2}{*}{ 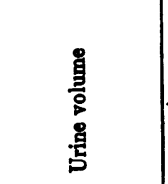 } & \multicolumn{2}{|c|}{$\begin{array}{l}\text { Dagenan } \\
\text { excreted } \\
\text { in urine }\end{array}$} & \multirow{2}{*}{ 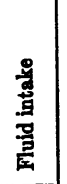 } & \multirow{2}{*}{ 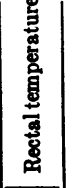 } & \multirow{2}{*}{ 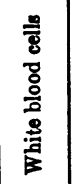 } & \multirow{2}{*}{ 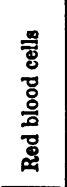 } & \multirow{2}{*}{ 을 } & \multirow{2}{*}{ 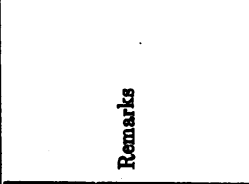 } \\
\hline & & & 홍 & $\$$ & 丞 & 8 & & 㺃 & 8 & & & & & & \\
\hline \multirow{3}{*}{$\begin{array}{c}\text { grams } \\
2 \text { grams Solu- } \\
\text { dagensn intra- } \\
\text { muscularly }\end{array}$} & May 7 & 5:30 p.m. & \multicolumn{2}{|c|}{ mom. per $100 \mathrm{cc}$} & \multicolumn{2}{|c|}{ mom. per $100 \mathrm{cc}$} & $\begin{array}{c}\text { cubic } \\
\text { contimeters }\end{array}$ & \multicolumn{2}{|c|}{ grams } & ca. & 104.5 & 17,200 & $\begin{array}{c}\text { mil } \\
\text { lions } \\
\text { per } \\
\text { c.mm. } \\
5.70\end{array}$ & $\begin{array}{c}\text { per } \\
\text { cent } \\
95\end{array}$ & N.P.N., 28 \\
\hline & & 6:00 p.m. & 2.1 & 1.9 & & & & & & & & & & & Neutrophils 85 per cent \\
\hline & & 7:30 p.m. & 3.7 & 3.3 & & & & & & & & & & & Right lower lobe involved \\
\hline \multirow{2}{*}{$\begin{array}{l}2 \text { grams Solu- } \\
\text { dagenan intre- } \\
\text { muscularly }\end{array}$} & & 8:30 p.m. & 4.2 & 4.0 & & & & & & & 102.6 & & & & $\begin{array}{l}\text { No soreness at site of in- } \\
\text { jection }\end{array}$ \\
\hline & & 10:30 p.m. & 6.6 & 5.6 & & & & & & & & & & & \\
\hline \multirow{2}{*}{$\begin{array}{l}2 \text { grams Solu- } \\
\text { dagenan intra- } \\
\text { muscularly }\end{array}$} & May 8 & 12:01 a.m & 6.2 & 5.2 & & & & & & & 101.2 & & & & \\
\hline & & 9:00 a.m. & 8.6 & 7.4 & 235 & 150 & 140 (S.G. $=1034)$ & .33 & .21 & 590 & 98.4 & 12,000 & 4.71 & 85 & \\
\hline \multirow{3}{*}{$\begin{array}{l}1 \text { gram Solu- } \\
\text { dagenan Intra- } \\
\text { muscularly }\end{array}$} & & 9:00 p.m. & 8.2 & 6.7 & 242 & 167 & 700 & 1.69 & 1.17 & 2,200 & 101.0 & & & & $\begin{array}{l}\text { No local or general reac- } \\
\text { tion to injections }\end{array}$ \\
\hline & & 10:00p.m. & 9.7 & 7.5 & & & & & & & & & & & \\
\hline & May 9 & 12:02 a.m. & 9.8 & 7.9 & & & & & & & 100.8 & & & & \\
\hline \multirow{2}{*}{$\begin{array}{l}1 \text { gram Solu- } \\
\text { dagenan intra- } \\
\text { museularly }\end{array}$} & & 9:00 a.m. & 6.0 & 5.2 & 333 & 211 & 300 & 1.00 & 0.63 & & 101.4 & & & & $\begin{array}{l}\text { Extengion to left lower lobe } \\
\text { in spite of levels in blood }\end{array}$ \\
\hline & & 11:20 a.m. & 6.7 & 5.8 & & & & & & & 103.4 & 8,900 & & 88 & \\
\hline \multirow{2}{*}{$\begin{array}{l}2 \text { grams Dagenan } \\
\text { per OB. }\end{array}$} & & 12:30 p.m. & 6.6 & 5.9 & 231 & 124 & 200 & 0.46 & 0.25 & & & & & & \\
\hline & & 2:30 p.m. & 7.8 & 6.6 & & & & & & & & & & & Very ill \\
\hline $\begin{array}{l}2 \text { grams Dagenan } \\
\text { per } \mathrm{Ob}_{\mathrm{s}}\end{array}$ & & 4:30 p.m. & 8.0 & 7.4 & & & & & & 2,160 & 103.0 & & & & \\
\hline $\begin{array}{l}2 \text { grams Dagenan } \\
\text { per Os. }\end{array}$ & & 8:00 p.m. & 12.1 & 11.0 & & & & & & & 101.0 & 6,200 & & & \\
\hline $\begin{array}{l}2 \text { grams Dagenan } \\
\text { per Ok. }\end{array}$ & & 11:45 p.m. & 14.4 & 12.9 & & & & & & & 101.4 & & & & \\
\hline $\begin{array}{l}2 \text { grams Dagenan } \\
\text { per Os. }\end{array}$ & May 10 & 4:00 a.m. & & & & & & . & & & 101.2 & & & & Much improved \\
\hline $\begin{array}{l}2 \text { grams Dagenan } \\
\text { per Os. }\end{array}$ & & 8:00 a.m. & & & & & & & & & 99.0 & 4,800 & 4.62 & 93 & \\
\hline $\begin{array}{l}11 \text { grams Dago- } \\
\text { nan per Os. }\end{array}$ & & 12:30 p.m. & & & 288 & 170 & 1,050 & 3.02 & 1.79 & & 98.8 & & & & \\
\hline
\end{tabular}


TABLE III-Continued

\begin{tabular}{|c|c|c|c|c|c|c|c|c|c|c|c|c|c|c|c|}
\hline \multirow[b]{2}{*}{ 長 } & \multirow[b]{2}{*}{ 宽 } & \multirow[b]{2}{*}{ 善 } & \multicolumn{2}{|c|}{$\begin{array}{l}\text { Concentration } \\
\text { of Dagenan } \\
\text { in blood }\end{array}$} & \multicolumn{2}{|c|}{$\begin{array}{c}\text { Concentration } \\
\text { of Dagenan } \\
\text { in urine }\end{array}$} & \multirow{2}{*}{$\begin{array}{l}\text { 鼻 } \\
\text { 量 } \\
\text { 总 }\end{array}$} & \multicolumn{2}{|c|}{$\begin{array}{l}\text { Dagenan } \\
\text { excreted } \\
\text { in urine }\end{array}$} & \multirow{2}{*}{$\begin{array}{l}\text { 总 } \\
\text { 总 } \\
\text { 堂 }\end{array}$} & \multirow{2}{*}{ 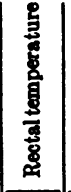 } & \multirow{2}{*}{ 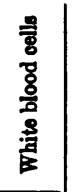 } & \multirow{2}{*}{ 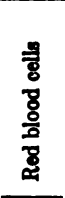 } & \multirow{2}{*}{ 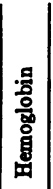 } & \multirow{2}{*}{ 竞 } \\
\hline & & & 宽 & 8 & 宽 & 8 & & : & 8 & & & & & & \\
\hline \multirow[t]{9}{*}{$\begin{array}{c}\text { grame } \\
\text { 1) grams Dage- } \\
\text { nan per Oa. }\end{array}$} & & 4:00 p.m. & \multicolumn{2}{|c|}{ mom. per 100 ce. } & \multicolumn{2}{|c|}{ mom. per 100 ce. } & $\begin{array}{l}\text { eubic } \\
\text { centimeters }\end{array}$ & \multicolumn{2}{|c|}{ orams } & $\boldsymbol{\alpha}$. & \multicolumn{2}{|l|}{99.0} & $\begin{array}{c}\text { mil- } \\
\text { lions } \\
\text { per } \\
\text { c.mm. }\end{array}$ & $\begin{array}{c}\text { per } \\
\text { cent }\end{array}$ & $\begin{array}{l}\text { Noutrophils only } 48 \text { per } \\
\text { cent } \\
\text { Dagenan discontinued }\end{array}$ \\
\hline & & 8:00 p.m. & 17.6 & 14.7 & & & & & & 5,000 & 100.0 & 4,800 & & & $\begin{array}{l}\text { Fuids by mouth and in- } \\
\text { travenously }\end{array}$ \\
\hline & May 11 & 12:01 a.m. & & & 123 & 78 & 1,600 & 1.97 & 1.25 & & 99.8 & & & & \\
\hline & & 9:00 a.m. & & & 170 & 112 & 2,500 & 4.25 & 2.80 & & 98.8 & 7,800 & 5.10 & & Neutrophils 56 per cent \\
\hline & & 11:30 a.m. & 12.3 & 11.7 & 221 & 112 & 350 & 0.73 & 0.39 & & 99.2 & & & & \\
\hline & & 4:00 p.m. & 10.4 & 9.4 & 139 & 88 & 650 & 0.90 & 0.57 & & 99.8 & & & & \\
\hline & & 11:00 p.m. & 6.9 & 5.9 & 82 & 57 & 1,800 & 1.48 & 1.03 & 4,800 & 100.2 & & & & \\
\hline & May 12 & $9: 00 \mathrm{s.m}$. & 4.1 & 3.8 & 73 & 45 & 1,900 & 1.39 & 0.87 & & 101.2 & 5,800 & 4.77 & 84 & $\begin{array}{l}\text { Signs of pneumonia er- } \\
\text { tending }\end{array}$ \\
\hline & May 13 & 9:00 a.m. & 1.6 & 1.5 & 42 & 28 & 2,450 & 1.03 & 0.69 & 6,050 & $\begin{array}{l}103.4 \\
100.2 \\
\end{array}$ & & & & Van den Bergh 1.54 units \\
\hline Total & & 7:00 p.m. & Trace & $\begin{array}{l}\text { Trace } \\
\text { v. \&. }\end{array}$ & 14 & $\boldsymbol{\theta}$ & 1,850 & 0.26 & 0.17 & & 102.2 & & & & Ictervs obvious \\
\hline \multirow{6}{*}{$\begin{array}{l}8 \text { grams Solu- } \\
\text { dagenan, intra- } \\
\text { venousis plus } \\
15 \text { grams bage- } \\
\text { nea by mouth }\end{array}$} & May 14 & 7:00 a.m. & $\begin{array}{l}\text { Slight } \\
\text { trace }\end{array}$ & $\begin{array}{c}\text { Slight } \\
\text { trace }\end{array}$ & 35 & 19 & 400 & 0.14 & 0.08 & 3,200 & 100.0 & & & & Rash on abdomen \\
\hline & & 7:00p.m. & $\begin{array}{l}\text { V. s. } \\
\text { trace } \\
\end{array}$ & Nil & 7 & 5 & 2,000 & 0.14 & 0.100 & 3,500 & 102.6 & & & & Van den Bergh 12 units \\
\hline & May 15 & 7:00 a.m. & \multicolumn{2}{|c|}{ Slight est trace } & 10 & 0 & 400 & 0.04 & 0.02 & & 100.0 & & & & Van den Bergh 15 units \\
\hline & & 7:00 p.m. & Nil & & 12 & 7 & 1,420 & 0.17 & 0.10 & 2,500 & $\overline{102.4}$ & 11,400 & 4.36 & 82 & \begin{tabular}{|l|}
$\begin{array}{l}\text { Liver } 21 \text { inchese below right } \\
\text { costal margin }\end{array}$ \\
\end{tabular} \\
\hline & May 16 & 7:00 p.m. & & & Trace & SI. trace & 480 & & & 2,800 & 99.6 & & & & \\
\hline & May 17 & 7:00 p.m. & & & $\begin{array}{l}\text { SL. tr. } \\
\text { ved. } \\
\text { tr. } \\
\end{array}$ & & 2,000 & & & 2,200 & 99.0 & 8,500 & 4.13 & 80 & Van den Bergh 23 units \\
\hline \multirow[t]{2}{*}{$\begin{array}{l}\text { Total dosage } 23 \\
\text { grams }\end{array}$} & Totals & & & & & & $\begin{array}{l}22.2 \\
\text { Liters }\end{array}$ & 18.00 & 12.12 & \begin{tabular}{|l|}
35 \\
Liters \\
\end{tabular} & & & & & $\begin{array}{l}\text { Liver receding. Thereafter } \\
\text { Van den Bergh receding } \\
\text { and normal on May } 28 . \\
\text { Complete recovery }\end{array}$ \\
\hline & & & \multicolumn{5}{|c|}{$\begin{array}{l}\text { Hereafter traces mere detected in the urine until } \\
\text { May 28th, or eighteen days after the last dose of } \\
\text { Dagenan had been given. }\end{array}$} & & & & & & & & \\
\hline
\end{tabular}

May 15 until May 28). This patient, therefore, excreted about 85 per cent of the drug originally administered.

No other case in the entire series showed such a prolonged excretion and the. assumption seems tenable that this was due to delay in freeing the body of the Solu-dagenan injected intramuscularly. If this should prove to be the case, it is a point worth consideration in view of the proven toxicity of drugs of this type.

\section{DISCUSSION}

In addition to the points which have been made, other impressions already recorded with respect to cases treated with sulphapyridine by mouth re- ceived support from the studies in these 4 cases treated by injections. At the risk of repetition certain points merit emphasis.

It is clearly evident that there must be wide variations in the ability of the human subject to absorb the drug from the gastro-intestinal tract. From two to three, four and even five times as much sulphapyridine must often be given by mouth to attain the concentrations in the blood observed after injection of the soluble sodium salt. By inference, and it is proven by analysis, much of the drug given by mouth must pass unabsorbed through the gastro-intestinal tract. This is an unsatisfactory aspect of this form of chemotherapy. It makes necessary frequent 
chemical estimations to ensure effective dosage and it greatly obscures any attempt at estimating the true toxicity of the drug (3).

From the findings in this series it seems safe to state that when a single dose of sulphapyridine is given by mouth the maximum concentration in the blood is reached in four to five hours. When given intramuscularly as sodium sulphapyridine or Solu-dagenan the maximum is attained in three to three and one-half hours. When this salt is injected intravenously there is for a short period a very high concentration in the blood but this falls after thirty minutes to a level which may be taken as the effective maximum concentration. This is not observed in cases treated orally or by intramuscular injection; for, in these, distribution is effected as the drug is taken into the general circulation.

Postmortem assays of the organs, tissues and fluids indicate a selective and unequal distribution; but, in general, arbitrary calculations based on the concentration of the drug in the blood and the weight of the patient enable one to estimate with remarkable accuracy the actual amount of the drug contained in the body at a given moment.

There has been a general tendency to be content with estimating the concentration of the free moiety in the blood as a guide to treatment. The findings in the series indicate that the procedure may fall far short of the desiderata for intelligent and safe therapy. The extraordinary increase in the highly toxic conjugated fraction which has been observed in cases with temporarily defective renal function constitutes a real danger in treatment. It has been demonstrated that the impairment of the kidneys may occur several days after the pnuemonic process has apparently been conquered and at times when the blood concentrations of free sulphapyridine are not excessively high.

In previous years it was noticed that the use of sulphanilamide in the treatment of Type III pneumonia not infrequently resulted in an accumulation of the drug in the blood. As much as $30 \mathrm{mgm}$. per $100 \mathrm{cc}$. were found in cases receiving less than 100 grains of sulphanilamide per diem. Excessively high concentrations only occurred, however, at the height of the febrile period and, in the absence of additional evidence to the contrary, they were attributed to temporary renal failure produced by the disease process.
The occurrence of acute renal insufficiency in recovering and afebrile cases on maintenance doses of sulphapyridine seems, on the other hand, to incriminate the drug itself. Some of the cases in the series developed sudden oliguria when the fluid intake was as much as $2,000 \mathrm{cc}$. in twentyfour hours. Nevertheless, acute renal insufficiency with accumulation of sulphapyridine in the blood never occurred without warning. A review of the protocols of such cases always revealed that on one or more previous occasions the urine volume had fallen below $750 \mathrm{cc}$. in a twentyfour-hour period. These facts force the conclusion that an accurate measurement of the urine passed in each twenty-four hours of treatment by chemotherapy is of paramount importance. At the first indication of defective renal function (urinary excretion falling below $1,000 \mathrm{cc}$. in twenty-four hours), fluids must be administered in large amounts and, if the concentration for the total drug in the blood is high, chemotherapy should at once be interrupted or terminated altogether.

With the existence or restoration of normal renal function, intravenous administration results in a very rapid excretion of the drug and a prompt decrease in the concentration in the blood. This should always be the first and it is probably the only effective method of combatting serious toxic manifestations resulting from this type of chemotherapy.

In this series the evidence seems to support the view that the conjugated form is excreted in the urine at a faster rate than is the free form. Although the kidneys are undoubtedly of chief importance in removing the drug from the body, it has been shown in cases receiving the drug by injection only that considerable amounts may be excreted into the bowel.

We are not able to state how much of the drug can be lost by perspiration or by the bowel but at least in cases suffering from pneumonia it would seem to be certain that other avenues of excretion in addition to the kidneys must be in active use.

\section{SUM MARY}

1. Data accumulated in a series of 90 cases of pneumonia treated by 2-(p-aminobenzenesulphonamido)-pyridine, M. \& B. 693 (Dagenan or sulphapyridine), have been applied to a study of 
the absorption, distribution and excretion of the drug in the human subject.

2. Tentative conclusions have been drawn from the findings in 88 cases which received Dagenan by mouth.

3. The results of chemical studies on 4 cases treated with chemotherapy by injection have been compared with the conclusions reached in the orally-treated cases.

4. The findings in both groups of cases have been compared and discussed.

The authors wish to record their thanks to Dr. H. K. Detweiler for his helpful suggestions in the preparation of this paper and to Miss M. Dolan for valuable technical assistance.

\section{BIBLIOGRAPHY}

1. Evans, G. M., and Gaisford, W. F., Treatment of pneumonia with 2-(p-aminobenzenesulphonamido)pyridine. Lancet, 1938, 2, 14.
2. Marshall, E. K., Jr., Determination of sulfanilamide in blood and urine. J. Biol. Chem., 1937, 122, 263.

Marshall, E. K., Jr., and Litchfield, J. T., Jr., Determination of sulfanilamide. Science, 1938, 88, 85.

3. Marshall, E. K., Jr., and Litchfield, J. T., Jr., Some aspects of the pharmocology of sulfapyridine. Read before the American Association of Physicians, Atlantic City, May 2, 1939.

4. O'Brien, E. J., and McCarthy, C. J., Staphylococcal septicaemia treated with M. \& B. 693. Lancet, 1938, 2, 1232.

Maxwell, J., Staphylococcal septicaemia treated with M. \& B. 693. Lancet, 1938, 2, 1233.

5. Peters, John P., Distribution and movement of water and solutes in human body. Yale J. Biol. and Med., 1933, 5, 431.

6. Stewart, J. D., Rourke, G. M., and Allen, J. G., Excretion of sulfanilamide. J. A. M. A., 1938, 110, 1885.

7. Stewart, J. D., Rourke, G. M., and Allen, J. G., Acetylation of sulfanilamide. Surgery, 1939, 5, 232. 